\title{
A JAZIDA PALEOLÍTICA DE CASTELO VELHO (RIACHOS, TORRES NOVAS). NOVOS ELEMENTOS PARA O SEU ESTUDO: A INDÚSTRIA LÍTICA DO LOCUS 2
}

\author{
Jỗo PEDRO CUNHA RiBEIRO(1)
}

Resumo:

Abstract:

\section{INTRODUÇÃo}

O lugar de Castelo Velho situa-se na margem esquerda do rio Almonda, imediatamente a Sul da povoação de Riachos, integrando-se em termos administrativos na freguesia de Riachos do concelho de Torres Novas, no distrito de Santarém. As coordenadas geográficas do seu ponto central são as

\begin{abstract}
A descoberta de uma nova ocupação arqueológica na jazida paleolítica do Castelo Velho ocorreu no decurso de trabalhos de investigação sobre o Paleolítico Inferior, na margem direita do rio Tejo, na área abrangida pelos concelhos do Entroncamento, Golegã e Torres Novas. Quando procedemos à relocalização desta jazida, ao seu estudo e enquadramento na cronoestratigrafia das formações quaternárias da região, detectou-se um depósito coluvionar que, localmente, se sobrepõe de forma parcial às formações fluviais do rio Tejo aí representadas - Ft4 e Ft5 - associado a uma significativa concentração de materiais líticos talhados. A posterior realização de uma escavação arqueológica no local possibilitou a recolha de uma indústria lítica com mais de 250 peças baseada na exploração local do quartzito sob a forma de calhaus rolados. O estudo desta colecção permitiu verificar a preponderância de uma cadeia operatória de debitagem centrípeta, não Levallois, associada à presença quase exclusiva de alguns utensílios sobre lasca, o que levou a associar a indústria lítica ao Paleolítico Médio. Tendo em conta a posição estratigráfica da coluvião e a pedogénese que a afecta, admite-se que a mesma se terá formado depois da deposição da última formação fluvial, localmente representada em Castelo Velho (Ft5), mas num momento anterior ao início da deposição da formação fluvial mais recente do rio Tejo (Ft6), o que está de acordo com a classificação proposta e sugere, aparentemente, uma datação relativamente antiga para a indústria no quadro do Paleolítico Médio em Portugal.
\end{abstract}

Palavras-chave: Bacia do Tejo; Plistocénico; Terraços; Paleolítico Médio.

\begin{abstract}
The paleolithic site of Castelo Velho (Riachos, Torres Novas). New elements for is study: the lithic industry from Locus 2

The discovery of a new archaeological occupation in the Paleolithic site of Castelo Velho occurred during a research campaign on Lower Paleolithic of the right bank of Tejo River, in the area of Entroncamento, Golegã and Torres Novas municipalities. When we were relocating, studying and matching this Lower Paleolithic site in the chronostratigraphy of the regional Quaternary deposits, we have found a colluvial deposit, partially overlaid to the terraces of Tejo River existing there - Ft4 and Ft5 - associated to a significant concentration of lithic implements. A later archaeological excavation in this deposit allowed to collect a lithic industry with more than 250 implements developed from local quartzite pebbles. The sudy of this assemblage show mainly the presence of a lithic reduction sequence based on a centripetal associate this lithic industry to the Middle Paleolithic. When observing the stratigraphical position of the colluvial deposit and its pedogenesis, we might admit that it was formed after the deposition of the last local terrace of Castelo Velho (Ft5), but in a moment that was previous to the beginning of the deposition of the most recent terrace of the Tejo River (Ft6), which are in accord with the proposal classification and leads us to a relatively old chronology of the industry inside the Portuguese Middle Paleolithic.
\end{abstract}

Key-words: Tejo River; Pleistocene; Terrace; Middle Paleolithic.

(1) Departamento de História da Faculdade de Letras da Universidade de Lisboa. Cidade Universitária, 1600-214 Lisboa. jpcunharibeiro@fl.ul.pt 
dezenas de metros sobre a adjacente planície aluvial do Almonda, da qual se encontra separada por uma vertente bem marcada e de forte pendor (Fig. 1).

A morfologia do local resultou da conservação do depósito de uma antiga formação fluvial quaternária do rio Tejo cuja base se encontra a cerca de $25 \mathrm{~m}$ sobre o leito actual do rio Tejo, o que corresponde a uma altitude absoluta de cerca de $38 \mathrm{~m}$, repousando localmente em discordância sobre o complexo detrítico miocénico. O topo aplanado do depósito, seccionando a parte superior da formação fluvial, atinge no seu ponto mais elevado a altitude de $48 \mathrm{~m}$.

O recorte do depósito, no alinhamento de outros depósitos similares do mesmo terraço do rio Tejo que nesta zona da sua margem direita se encontram bem preservados a montante e para jusante (ZBYSZEWSKI et al. 1971), foi determinado pelo encaixe da rede de drenagem actual. Esta encontra-se localmente representada a oeste pelo rio Almonda e a este pelo entalhe bem mais suave de uma pequena linha de água tributária deste afluente da margem direita do rio Tejo.

Nesta última área assinala-se também a presença de uma outra formação fluvial do rio Tejo situada a uma altitude inferior. A sua base situa-se a cerca de $10 \mathrm{~m}$ sobre o leito actual do rio Tejo, que corresponde a uma altitude absoluta de $22 \mathrm{~m}$, enquanto o topo ultrapassa por vezes os $36 \mathrm{~m}$ - permitindo o seu posicionamento escalonado relativamente à formação fluvial inicialmente referida deduzir a maior antiguidade da primeira em relação à segunda.
Encaixada lateralmente sobre a base da formação mais antiga, seccionando o substrato miocénico e sobrepondo-se também localmente ao rebordo da formação fluvial mais recente, assinalou-se na vertente nascente da plataforma do Castelo Velho a presença de uma coluvião essencialmente constituída por materiais remobilizados de depósitos detríticos mais antigos.

\section{AnteCEDENTES}

A importância arqueológica da área onde se situa esta jazida paleolítica foi num primeiro momento destacada pela descoberta no local de "fragmentos de tijolos, de tégulas e de ânforas romanas" situação essa a que não será alheia a origem do próprio topónimo de Castelo Velho (ZBYSZEWSKI et al. 1974).

No mesmo local recolheram-se também uma centena de peças líticas talhadas, quase exclusivamente em quartzito, cuja relativa atipicidade foi imputada à fraca qualidade dos calhaus rolados utilizados como matéria-prima (ZBYSZEWSKI et al. 1974). Mesmo assim, o estudo de tais materiais levou à divisão da colecção exumada por três distintas séries, definidas em função da alteração física das respectivas peças. Integrando as duas mais antigas séries, uma e duas peças, em qualquer dos casos fisicamente alteradas, ambas foram, não obstante a sua parca representatividade, genericamente associadas ao Acheulense: "possivelmente do Acheulense médio

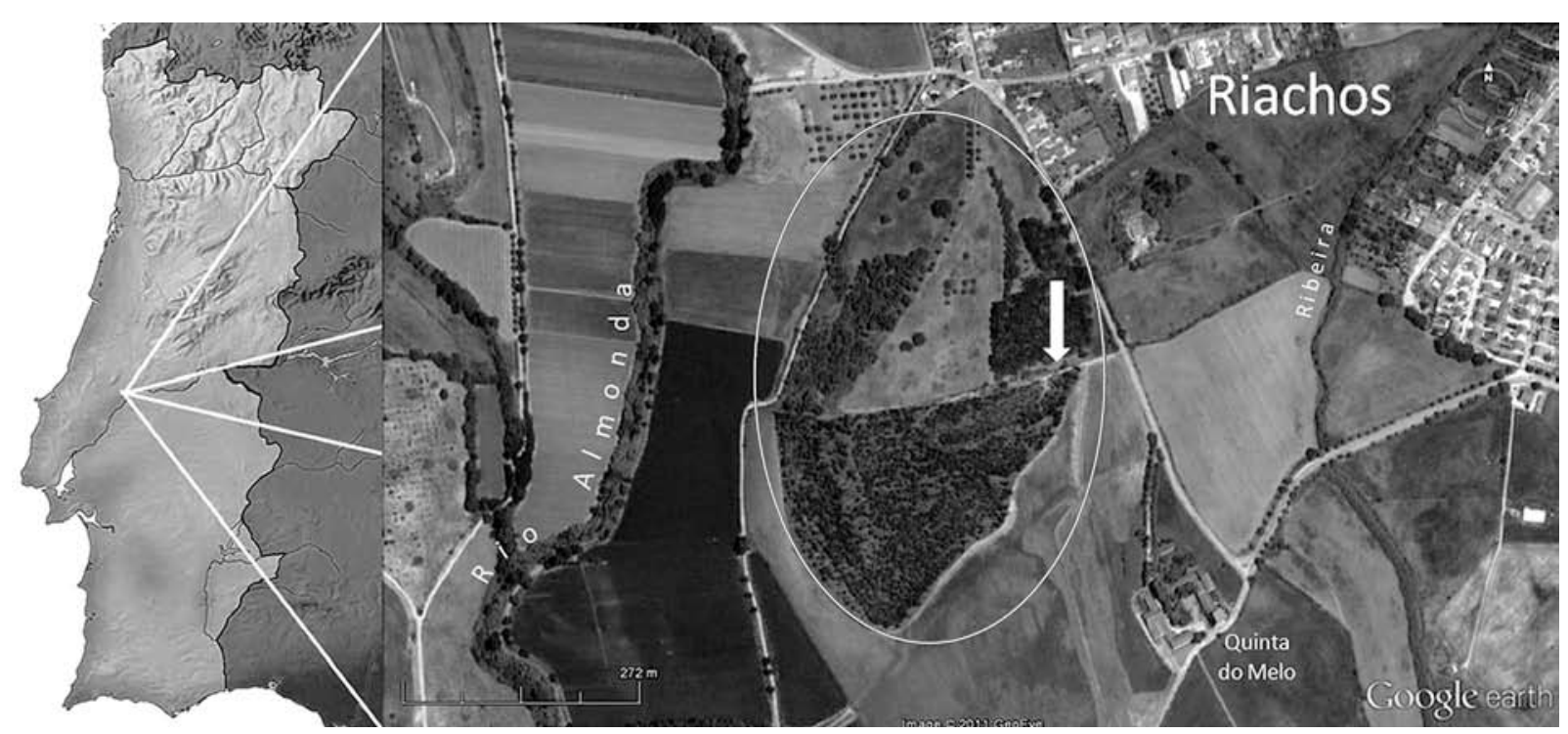

Fig. 1. Vista área da área do Castelo Velho com a respectiva plataforma circunscrita pela linha branca identificando-se, imediatamente a Oeste, a planície aluvial do rio Almonda. Imagem do Google Earth (4-7-2009), a $1160 \mathrm{~m}$ de altitude.

Fig. 1. Aerial view over the area of Castelo Velho with its platform surrounded by a red line. West, the floodplain of Almonda River. Image from the Google Earth (04-07-2009). 
ou superior" (ZBYSZEWSKI et al. 1974). Bem mais numerosa, a terceira série reunia as peças não alteradas, consideradas do "Acheulense final passando para o Paleolítico médio de fácies languedocense", asserção combinatória decorrente da presença de um conjunto maioritário de macro-utensílios tradicionalmente conectados com as industrias líticas acheulenses - "calhaus truncados", "calhaus raspadores", "calhaus trabalhados" - e de dois outros artefactos identificados como "coups-de-poing", em associação com um conjunto de peças consideradas mustierenses, onde se incluíam alguns utensílios sobre lascas e lascas de "técnica mustierense e tayacense".

No estudo que realizámos das estações paleolíticas da margem direita do rio Tejo na área dos concelhos de Torres Novas, do Entroncamento e da Golegã, tivemos oportunidade de relocalizar esta jazida paleolítica no contexto da revisão que concomitantemente se efectuou da cronoestratigrafia das principais formações quaternárias da região e reunir ainda uma pequena colecção de materiais líticos inequivocamente associáveis ao depósito de terraço aí representado. Cerca de dezena e meia das 71 peças encontradas foram mesmo exumadas no amplo corte transversal que secciona a parte meridional do referido depósito de poente para nascente (CUNHA-RIBEIRO et al. 1995). O sumário estudo desta nova colecção permitiu integrá-la no arquétipo das indústrias acheulenses da região, destacando-se em particular o reduzido número de bifaces nela representado, bem como a ausência de machados de mão (CUNHA-RIBEIRO 1996-1997). A presença de distintas estratégias de exploração entre os núcleos reunidos sugere, por seu turno, a presença de cadeias operatórias de debitagem relativamente diversificadas e de pendor oportunista.

Paralelamente, identificou-se na coluvião a presença de uma indústria lítica mais numerosa e com características tecno-tipológicas claramente distintas do conjunto anterior, justificando a individualização do seu estudo. Tendo em conta a proveniência desta nova indústria de um local bem circunscrito e claramente distinto do ponto de vista geoarqueológico da origem dos restantes achados anteriormente aí realizados, optou-se por associá-la a um novo locus, designado por Locus 2 de Castelo Velho ou, de forma abreviada, por Castelo Velho 2.

\section{Trabalhos Realizados}

\subsection{Escavação}

Para determinar de forma inequívoca as reais condições de jazida dos materiais provenientes deste novo locus e, ao mesmo tempo, recolher uma amostragem de peças talhadas suficientemente significativa para estabelecer a sua caracterização, optou-se por uma breve intervenção arqueológica no local, através da qual se procedeu ao levantamento do corte que secciona os vários depósitos aí representados e à realização de uma pequena escavação na coluvião.

Os trabalhos iniciaram-se com o levantamento do corte que com uma orientação Oeste/Este secciona a totalidade das formações representadas no lugar do Castelo Velho, acompanhando o atravessamento da plataforma por um caminho de pé posto que se dirige para a vizinha planície aluvial do rio Almonda (Fig. 2). Para o efeito efectuou-se o desenho parcial do corte a uma escala original de $1 / 200$, exagerada na vertical para $1 / 100$, de que resultou a posterior reprodução digital que se apresenta na Fig. 3.

A análise e descrição do corte permitiram registar a seguinte sequência estratigráfica:

1. Substrato miocénico constituído por um sedimento argilo-arenoso de cor castanha clara, cujo topo se encontra seccionado no sector ocidental e central do corte por uma superfície de erosão relativamente regular, situada a de cerca de 38-40 m de altitude absoluta, evidenciando para oriente uma inclinação que

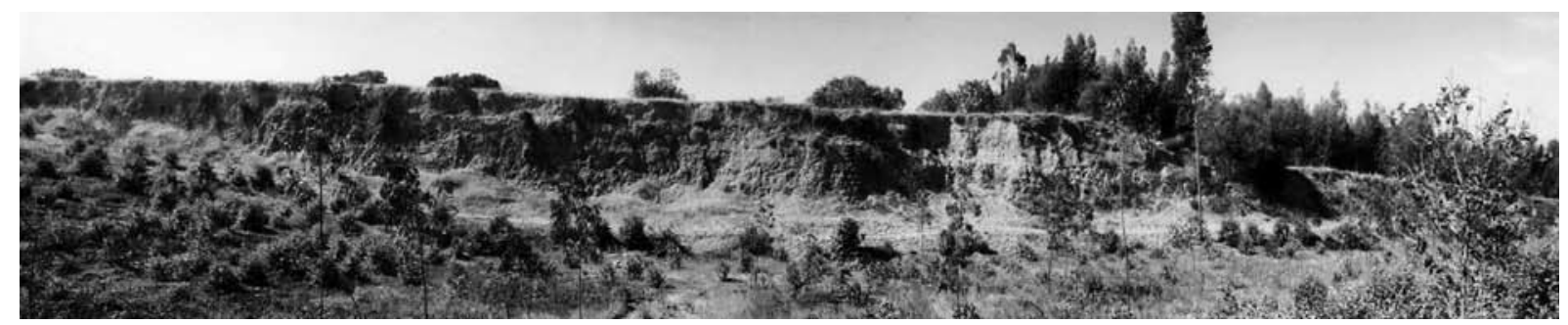

Fig. 2. Vista panorâmica do corte que secciona a plataforma do Castelo Velho, de oeste para este, com a direcção de $N$ $75 \mathrm{E}$, observando-se o rebordo que delimita a nascente a formação fluvial mais antiga, após o qual surge o encaixe do depósito coluvionar.

Fig. 2. Panoramic view of the cutting of Castelo Velho platform, from West to East (N 75 E). The edge of the oldest terrace appears at the right, before the incision of the colluvium. 


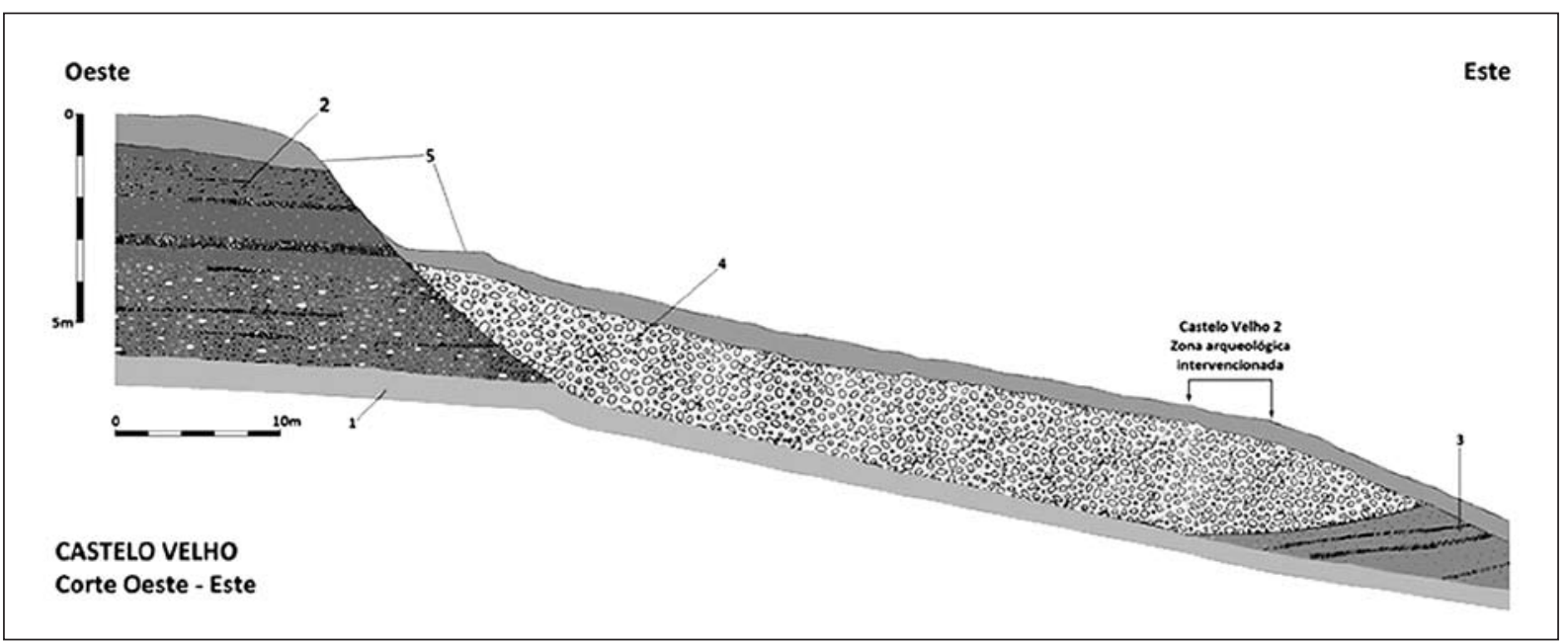

Fig. 3. Desenho parcial do corte que secciona a plataforma de Castelo Velho, de oeste para este, com a direcção N 75 E, indicando-se a implantação da zona escavada. 1 - Miocénico; 2 - Terraço Ft4; 3 - Terraço Ft5A; 4 - Coluvião; 5 - Terra humosa superficial.

Fig. 3. Section of the cutting of Castelo Velho platform, from West to East, showing the excavated area. 1 - Miocene; 2 - Terrace Ft4; 3 - Terrace Ft5; 4 - Colluvium; 5 - Humose surface level.

acompanha localmente o entalhe mais recente do Tejo;

2. Ocupando os sectores ocidental e central do corte, numa extensão de cerca de $70 \mathrm{~m}$, surge sobre o substrato miocénico o testemunho de uma antiga formação fluvial do rio Tejo que ao longo da sua extensão apresenta uma espessura média de cerca de $5 \mathrm{~m}$. Na sua base esta formação é constituída por uma cascalheira com $2 \mathrm{~m}$ de potência, formada por calhaus rolados de quartzito e quartzo de dimensões variáveis, atingindo e ultrapassando nalguns casos o seu eixo maior os $25 \mathrm{~cm}$, integrados numa matriz areno-argilosa onde se dispõem de forma aparentemente não organizada. Pontualmente, contudo, observam-se no seu interior alguns níveis de calhaus rolados dispostos horizontalmente em leitos pouco espessos e não muito extensos. Sobrepõe-se-lhe um nível com uma textura areno-argilosa que chega a atingir 3,5 $\mathrm{m}$ de espessura, onde se inserem de forma descontínua e por vezes muito esparsa leitos de calhaus rolados de menores dimensões, mas com uma composição petrográfica similar, dispostos segundo uma estratificação novamente horizontal e espraiando-se por toda a extensão da área observada. Em termos pedológicos este depósito de terraço suporta um importante solo vermelho localmente afectado por fenómenos de hidromorfia. Designado no estudo que realizámos dos principais depósitos quaternários da região como formação fluvial Ft4 (CUNHA-RIBEIRO 2011), corresponde aos depósitos de terraços Q3 assinalados na Carta Geológica de Portugal na escala 1/50 000 (ZBYSZEWSKI et al. 1971) ${ }^{1}$.

3. Marginalmente representada na extremidade oposta do corte, surge a uma cota mais baixa, aparentemente representada pelo seu rebordo marginal, o topo de uma outra formação fluvial que localmente não evidencia continuidade estratigráfica com a formação fluvial anterior. Trata-se de um segundo depósito de terraço com uma sedimentação predominantemente areno-argilosa em que se integram leitos delgados de pequenos e médios calhaus rolados dispostos de forma sub-horizontal (fim de sequência?). No já referido estudo sobre as formações quaternárias da região (CUNHA-RIBEIRO 2011), corresponde à formação fluvial Ft5 do rio Tejo, associável a parte dos depósitos de terraços Q4 cartografados na Carta Geológica de Portugal na escala 1/50 000 (ZBYSZEWSKI et al. 1971).

4. Depósito formado essencialmente por calhaus rolados de pequena e média dimensão, de quar-

Estes mesmos terraços Q3 foram associados em estudos mais recentes a um terraço T4, integrado num escalonamento dos terraços do rio Tejo definido a montante, entre Tomar e Vila Nova da Barquinha (MARTINS et al. 2010b), aparentemente equivalente de forma genérica ao reconhecido por nós a jusante, entre o Entroncamento e a Foz do rio Alviela (CUNHA-RIBEIRO 2011) 


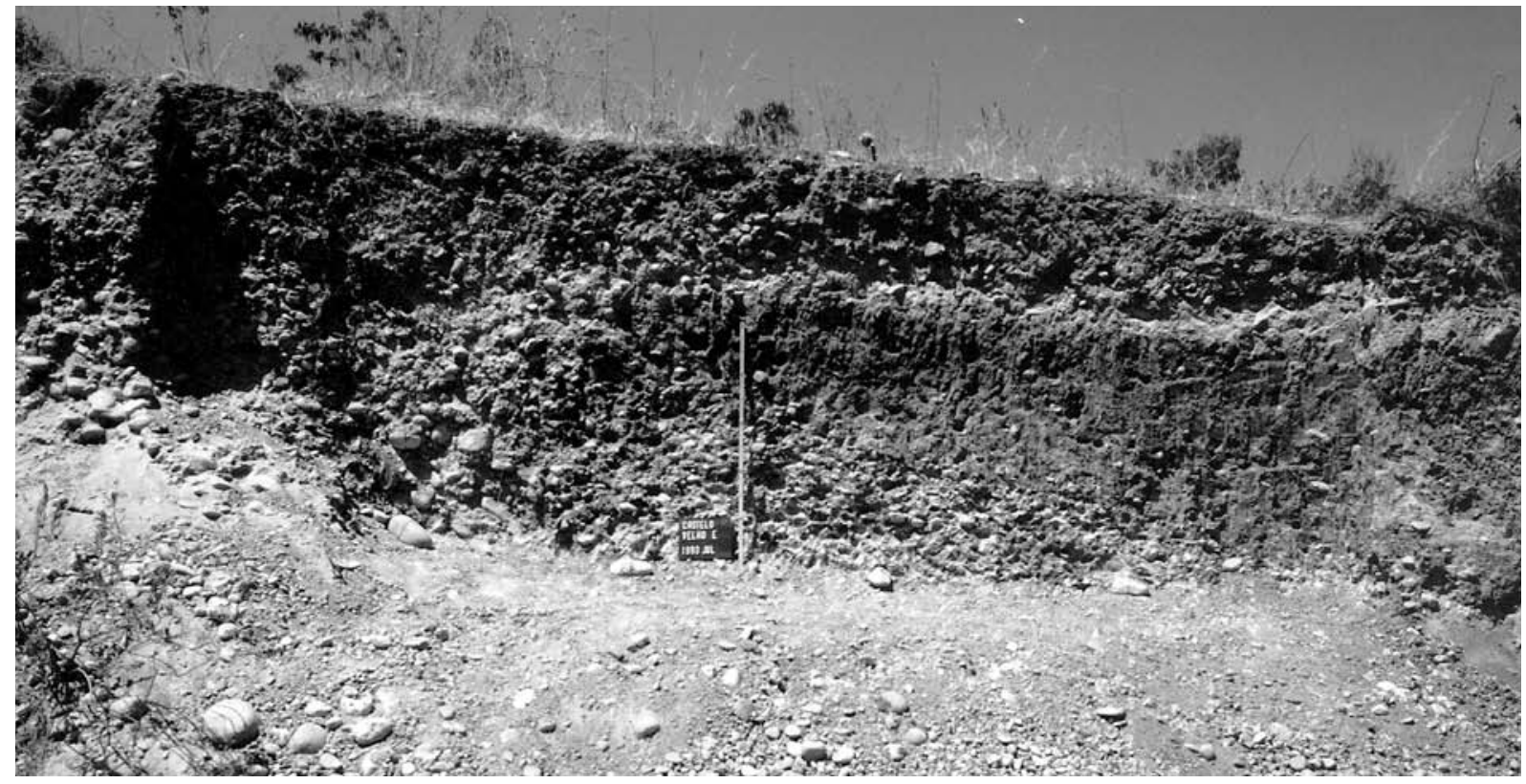

Fig. 4. Vista geral do aspecto final da zona escavada (dimensão da escala: $1 \mathrm{~m}$ ). A direcção do corte que aí se observa é coincidente com a do corte que atravessa a plataforma de Castelo Velho, seccionando as várias formações detríticas aí representadas.

Fig. 4. General view of the excavation área (scale dimension: 1 meter). The direction of cutting coincides with the cutting that goes through the platform.

tzito e de quartzo, que se integram de forma não organizada numa matriz areno-argilosa, por vezes de fracção bastante fina e com uma acentuada compacticidade, características estas que se expressam de forma homogénea por toda a zona do depósito seccionada pelo corte. Pela sua estrutura sedimentar e posicionamento, em sobreposição às duas formações fluviais já descritas, torna-se evidente a sua associação a uma coluvião.

5. Nível superficial de terras mais escurecidas, ricas em raízes e outras matérias orgânicas, que colmata a totalidade dos depósitos aí existentes, espraiando-se de forma contínua sobre a superfície aplanada que seccionou o topo da formação fluvial mais antiga. O seu desenvolvimento é, porém, interrompido pelo ressalto topográfico que delimita a nascente o rebordo da formação fluvial mais elevada, para em seguida se espraiar de novo de forma ligeiramente mais adelgaçada ao longo da ligeira vertente definida pelo topo da coluvião e da formação fluvial mais recente.

Note-se que à semelhança da formação fluvial mais antiga (Ft4), quer a formação fluvial mais re- cente - Ft5 - quer a coluvião, suportam um solo vermelho bem desenvolvido, levantando-se naturalmente a questão se é possível associá-los a uma ou mais fases de alteração.

Em seguida procedeu-se à abertura de uma pequena área de escavação na extrema nascente da coluvião, zona onde este depósito não só apresentava uma maior potência de sedimentos, como também deixava transparecer a presença de uma concentração mais significativa de materiais líticos talhados 2 (Fig. 4).

As dificuldades registadas no processo de remoção do sedimento, decorrente da sua extrema compacticidade, restringiram a área da intervenção à escavação de um sector de $5 \mathrm{~m}$ adjacente ao corte, através da implantação de uma quadrícula de $5 \mathrm{~m}^{2}$ alinhada com a própria base do corte. Tendo em conta a estrutura sedimentar do depósito, bem como a dispersão aleatória dos materiais líticos talhados no interior da própria coluvião, situação essa desde logo observada nas peças que inicialmente se exumaram no corte, apenas se procedeu ao registo da sua associação a cada uma das cinco quadrículas métricas em que se dividiu a área intervencionada: $\mathrm{C} 1, \mathrm{C} 2, \mathrm{C} 3, \mathrm{C} 4$ e $\mathrm{C} 5$.

2 Nos trabalhos realizados, além do signatário, participaram João Maurício e Pedro Souto, da Sociedade Torrejana de Espeleologia e Arqueologia. 


\subsection{Estudo do espólio}

Ao todo recolheram-se 286 peças líticas talhadas em Castelo Velho 2, 92 das quais não foi possível associar a nenhuma das quadrículas de referência, já que haviam sido recolhidas à superfície, na base do corte, ou dele tinham sido mesmo retiradas aquando da descoberta da importância arqueológica do local.

A repartição dos materiais exumados no decurso da escavação pelas diferentes quadrículas revelou-se, por seu turno, bastante equitativa, muito embora a diminuta dimensão da área escavada não permita retirar de tal facto qualquer outra conclusão. Em todo caso, a cuidada prospecção realizada ao longo do corte permitiu verificar que a concentração de materiais líticos talhados no depósito coluvionar ocorria significativamente na sua zona mais encaixada, a nascente, precisamente onde se implantou a escavação.

Relativamente à matéria-prima utilizada é claro o predomínio do quartzito sob a forma de seixos rolados (93\%), tendo-se para o efeito recorrido ao seu aprovisionamento entre os calhaus rolados de média e pequena dimensão que integram o próprio depósito coluvionar. A mesma situação verifica-se, aliás, em relação ao quartzo, ainda que a sua presença seja bem menos significativa (3,5\%). Já o sílex, com uma representação residual idêntica à do quartzo $(3,5 \%)$, provinha manifestamente do exterior do depósito, muito embora o seu aproveitamento se confinasse à presença de algumas lascas pouco expressivas, num ou noutro caso retocadas (Quadro 1).

Quanto ao seu estado físico, a grande maioria das peças apresenta arestas vivas $(89,2 \%)$, correspondendo o remanescente a materiais cujas arestas evidenciam apenas um ligeiro boleamento, frequentemente indissociável da própria qualidade da matéria-prima utilizada (Quadro 2). Muitas das peças recolhidas encontram-se também superficialmente impregnadas pela coloração avermelhada do solo suportado pela coluvião.

Quer no que se refere às matérias-primas representadas (Quadro 3), quer em relação ao estado físico dos seus constituintes (Quadro 4), os materiais exumados no decurso da escavação e as peças recolhidas no próprio corte ou nas suas imediações, mas à superfície, evidenciam uma composição e características muito próximas. A estatística das principais dimensões dos dois conjuntos não apresenta também qualquer diferenciação significativa entre eles, justificando ambas asserções o seu estudo como um todo.

À excepção de oito peças classificadas como fragmentos de talhe e de um único utensílio nucleiforme, as restantes peças provenientes de Castelo Velho 2 distribuem-se por um numeroso conjunto de lascas (226 peças) e um grupo menos numeroso de núcleos (51 peças), o que resulta numa relação proporcional entre ambos os conjuntos ligeiramente

Quadro 1. Matérias-primas e estado físico dos materiais líticos de Castelo Velho 2.

Table 1. Raw materials and the degree of erosion of the artifacts from Castelo Velho 2.

\begin{tabular}{|l|c|c|c|c|c|c|}
\hline \multirow{2}{*}{} & \multicolumn{2}{|c|}{ Arestas boleadas } & \multicolumn{2}{c|}{ Arestas vivas } & \multicolumn{2}{c|}{ Totais } \\
\cline { 2 - 7 } & $\mathbf{N .}^{\mathbf{0}}$ & $\mathbf{\%}$ & $\mathbf{N .}^{{ }^{\mathbf{0}}}$ & $\mathbf{\%}$ & $\mathbf{N .}^{{ }^{*}}$ & $\mathbf{\%}$ \\
\hline Quartzito & 29 & 93,5 & 237 & 92,9 & 266 & 93 \\
\hline Quartzo & & & 10 & 3,9 & 10 & 3,5 \\
\hline Sílex & 2 & 6,5 & 8 & 3,2 & 10 & 3,5 \\
\hline \multicolumn{1}{|c|}{ Totais } & 31 & 18,8 & 255 & 89,2 & 286 & \\
\hline
\end{tabular}

Quadro 2. Matérias-primas dos materiais de superfície e dos recolhidos na escavação.

Table 2. Raw materials of the surface artifacts and those collected in the excavation.

\begin{tabular}{|l|c|c|c|c|}
\hline \multirow{2}{*}{} & \multicolumn{2}{|c|}{$\begin{array}{c}\text { Materiais de } \\
\text { superfície }\end{array}$} & \multicolumn{2}{c|}{$\begin{array}{c}\text { Materiais recolhidos } \\
\text { na escavação }\end{array}$} \\
\cline { 2 - 5 } & $\mathbf{N .}^{\mathbf{0}}$ & $\mathbf{\%}$ & $\mathbf{N .}^{\mathbf{0}}$ & $\mathbf{\%}$ \\
\hline Quartzito & 82 & 89,1 & 184 & 94,8 \\
\hline Quartzo & 4 & 4,4 & 6 & 3,1 \\
\hline Sílex & 6 & 6,5 & 4 & 2,1 \\
\hline
\end{tabular}

Quadro 3. Estado físico dos materiais de superfície e dos recolhidos na escavação.

Table 3. The degree of the erosion of the surface artifacts and those collected in the excavation.

\begin{tabular}{|l|c|c|c|c|}
\hline \multirow{2}{*}{} & \multicolumn{2}{|c|}{$\begin{array}{c}\text { Materiais de } \\
\text { superfície }\end{array}$} & \multicolumn{2}{c|}{$\begin{array}{c}\text { Materiais } \\
\text { recolhidos na } \\
\text { escavação }\end{array}$} \\
\cline { 2 - 5 } & N. $^{\mathbf{2}}$ & \% & N. $^{{ }^{0}}$ & \% \\
\hline Arestas boleadas & 82 & 89,1 & 184 & 94,8 \\
\hline Arestas vivas & 4 & 4,4 & 6 & 3,1 \\
\hline
\end{tabular}


Quadro 4. Estatística das dimensões dos materiais de superfície e dos recolhidos na escavação.

Table 4. Statistics dimensions of the surface artifacts and those collected in the excavation.

\begin{tabular}{|l|c|c|c|c|c|c|}
\hline \multirow{2}{*}{} & \multicolumn{3}{|c|}{ Materiais de superfície } & \multicolumn{3}{c|}{$\begin{array}{c}\text { Materiais recolhidos } \\
\text { na escavação }\end{array}$} \\
\cline { 2 - 7 } & C & I & e & C & I & e \\
\hline N & 80 & 80 & 80 & 175 & 175 & 175 \\
\hline MAX & 122 & 911 & 45 & 114 & 108 & 62 \\
\hline MIN & 17 & 12 & 5 & 19 & 11 & 5 \\
\hline Média & 43,9 & 37 & 15,7 & 50,4 & 41,7 & 20,1 \\
\hline Mediana & 39 & 32,5 & 13 & 46 & 40 & 17 \\
\hline Desvio Padrão & 17,91 & 15,32 & 8,45 & 19,22 & 16,53 & 11,8 \\
\hline
\end{tabular}

superior a 4 para 1 . Mesmo tendo em conta que os núcleos envolvidos apresentam em média mais de sete extracções, bem como o contexto claramente secundário a que esta indústria se encontra associada, esta relação proporcional entre lascas e núcleos não deixa de conferir à colecção exumada alguma representatividade.

O estudo das lascas abarcou um total de 230 peças, nelas se incluindo não apenas 17 utensílios sobre lasca, mas também quatro outras lascas utilizadas como suporte de núcleos. Tirando 10 lascas em sílex $(4,3 \%)$ e outras 8 em quartzo $(3,3 \%)$, as restantes resultaram do aproveitamento claramente preferencial do quartzito como matéria-prima $(92,2 \%)$, correspondendo o seu fraccionamento à prevalência de uma estratégia de exploração da matéria-prima sob a forma de calhaus rolados. Na sua maioria, tratava-se de peças com arestas vivas $(89,1 \%)$, apresentando as restantes um embotamento pouco marcado dos respectivos gumes e/ou arestas de talhe.

Para a classificação das lascas recorreu-se a uma metodologia já por nós testada no estudo de outras colecções arqueológicas (CUNHA-RIBEIRO 1992-1993, 1999) e que foi criada originalmente para o estudo de indústrias líticas sobre calhaus rolados de quartzito e de quartzo (TAVOSO 1978).

À parte de um conjunto 67 lascas em que a eliminação, por fragmentação, dos principais estigmas de talhe nos levou a agrupar entre os chamados fragmentos de lasca, as restantes peças estudadas correspondem maioritariamente a lascas de primeira geração $(65,5 \%)$, evidenciando em paralelo um claro predomínio dos talões corticais $(69 \%)$ sobre os lisos $(21,4)$, enquanto as peças cujo talão foi eliminado estão residualmente representada $(6 \%)$. Os índices de facetagem amplo e estrito evidenciam também valores baixos - 4,5 e 1,5, respectivamente, enquanto o índice Levallois técnico é nulo.

O elevado número de lascas de primeira geração que apresentam ao longo de um dos seus bordos um dorso cortical, tendencialmente aplanado e invasor ou marginal e abrupto, prolongando-se ou não para a zona distal da peça, indiciam um claro desenvolvimento lateral da debitagem, padrão este compatível com a exploração de calhaus rolados de quartzito ou de subprodutos deles derivados como suportes quase exclusivos da matéria-prima utilizada.

$\mathrm{Na}$ análise dos 51 núcleos inventariados ressalta igualmente a utilização preferencial do quartzito como matéria-prima - apenas foi identificado um núcleo explorado a partir de um calhau rolado de quartzo - e o renovado predomínio das peças com arestas de talhe vivas, dado que apenas em seis das peças contabilizadas se detectou um ligeiro embotamento de tais arestas. Não entrando em linha de conta com 11 peças cuja ligeira fragmentação não permitiu identificar muitos dos atributos considerados relevantes para a classificação dos núcleos, resulta da análise das restantes 40 peças a clara preferência pelo aproveitamento de calhaus rolados como suporte (21 peças), ainda que entre outras 11 peças esse mesmo atributo se revelasse indeterminável. As restantes 8 peças, por seu turno, testemunham de forma equitativa a utilização de calotes e de lascas como suportes.

Curiosamente, ou talvez não, o aprovisionamento local da matéria-prima e a abundância desta sob a forma de calhaus rolados, não impediu que $3 / 5$ dos núcleos se apresentassem intensamente explorados, embora apenas um único núcleo tenha sido considerado esgotado e os restantes revelassem uma sumária exploração.

$\mathrm{O}$ estudo destes produtos de talhe baseou-se no sistema classificativo desenvolvido por Manuel Santonja para as indústrias paleolíticas de quartzito da Meseta Ibérica (SANTONJA 1984-1985), o qual privilegia na individualização de cada grupo de núcleos considerado o desenvolvimento de determinadas 
estratégias de exploração, em detrimento da valorização dos atributos morfológicos anteriormente prevalecentes na classificação destas peças.

Não sendo muito numeroso, o conjunto de núcleos estudados distribui-se por diversos grupos e subgrupos do sistema classificativo adoptado.

Em termos meramente quantitativos destacam-se os núcleos com uma exploração unifacial baseada na obtenção de extracções adjacentes e unipolares, comummente associados ao grupo II, os núcleos com uma estratégia operatória bifacial, alicerçada na extracção alternante de lascas em torno de uma aresta situada em posição equatorial em relação ao volume do suporte, conectados com o grupo $\mathrm{V}$, e os núcleos do grupo IV, com uma exploração expedita, assente no aproveitamento do negativo de uma anterior extracção como plano de percussão para a obtenção de uma nova lasca, conduzindo amiúde a sua continuada exploração à definição de morfologias tendencialmente globulares. No total estes três grupos integram 2/3 dos núcleos estudados, enquanto os restantes grupos e subgrupos de núcleos identificados têm uma representação numericamente inferior.

Uma análise circunstanciada das realidades tecnológicas envolvidas permite, porém, verificar que alguns destes núcleos e outros associados aos grupos e subgrupos quantitativamente menos representados sugerem o esboço de estratégias de exploração mais complexas e noutros casos reportam-se a situações de transição entre alguns dos grupos de núcleos considerados, testemunhando mesmo por vezes processos de reconversão das estratégias de exploração envolvidas.

O grupo I, reunindo 3 peças com um reduzido número de extracções dispostas de forma não organizada, destaca-se pela sua diminuta representatividade num contexto onde a ampla disponibilidade da matéria-prima poderia ter facilitado a multiplicação de testes e um maior desperdício no aproveitamento dos suportes. Uma das peças indicia mesmo o esboçar de uma estratégia de exploração que a aproxima dos núcleos do grupo II, grupo este representado por um conjunto de 11 núcleos, maioritariamente desenvolvidos a partir de calhaus rolados (7 peças), parte dos quais explorados de forma intensiva ( 5 peças), deixando mesmo entrever nalguns casos uma ablação significativa do volume original dos respectivos suportes (Fig. 5). Mas se alguns destes núcleos do grupo II, revelando-se intensamente explorados, se esgotariam na continuação da sua própria estratégia de exploração, casos há em que o progressivo desenvolvimento periférico do talhe a partir de uma superfície cortical aproveitada como plano de percussão terá conduzido à adopção de uma

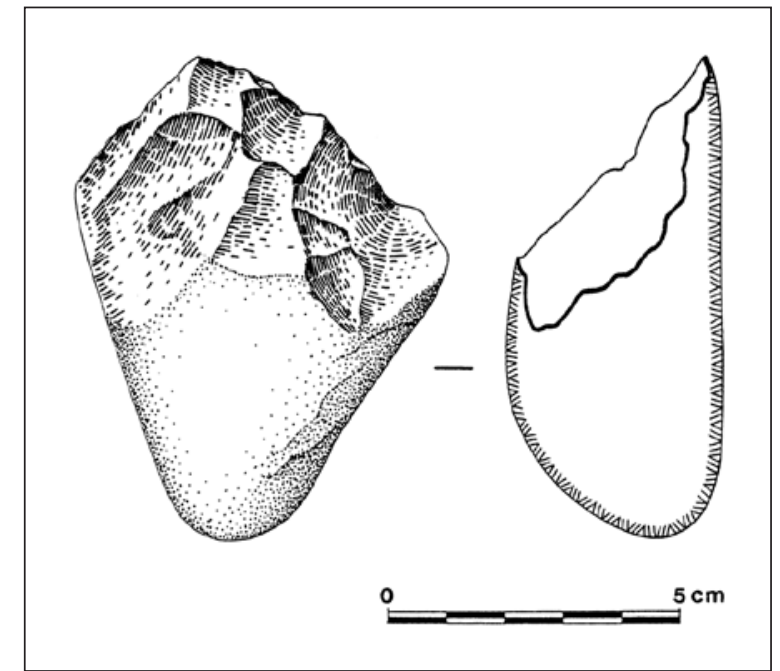

Fig. 5. Núcleo do grupo II sobre pequeno calhau rolado. Fig. 5. Core from the group II on a quartzite flattened pebble.

estratégia de exploração característica do grupo III. A identificação de uma peça claramente na transição entre os dois referidos grupos reforça, aliás, esta hipótese.

No entanto, dois dos três núcleos formalmente associados ao grupo III, cujas extracções oblíquas que os caracterizam recortam um plano de percussão cortical, não constituem aparentemente a afirmação de uma estratégia autónoma de debitagem. Trata-se antes de pré-formas de núcleos com extracções centrípetas obtidas a partir de um plano de percussão cortical, correspondendo mesmo uma das peças contabilizadas a uma clara situação de transição para o subgrupo VIc (Fig. 6). Um terceiro núcleo que foi integrado neste grupo testemunhava, por seu turno, a reutilização de um núcleo centrípeto sem preparação do plano de percussão, inicialmente associado ao subgrupo VIc, através do aproveitamento como plano de percussão para a extracção de levantamentos períféricos e oblíquos da face de exploração original, não se podendo contudo descartar a possibilidade de se estar antes perante a reconfiguração do próprio plano de percussão original de um núcleo centrípeto (Fig. 7).

Os núcleos, explícita e formalmente associados ao desenvolvimento de estratégias de exploração centrípetas, repartem-se equitativamente, por seu turno, entre os que não evidenciam qualquer preparação prévia do plano de percussão, aproveitando em geral para o efeito a regularidade das superfícies corticais remanescentes nos respectivos suportes (subgrupo VIc), e os que apresentam uma preparação pelo menos parcial do respectivo plano de percussão (subgrupo VIb). No seu conjunto perfazem um total de 7 peças, todas elas intensamente exploradas, num 


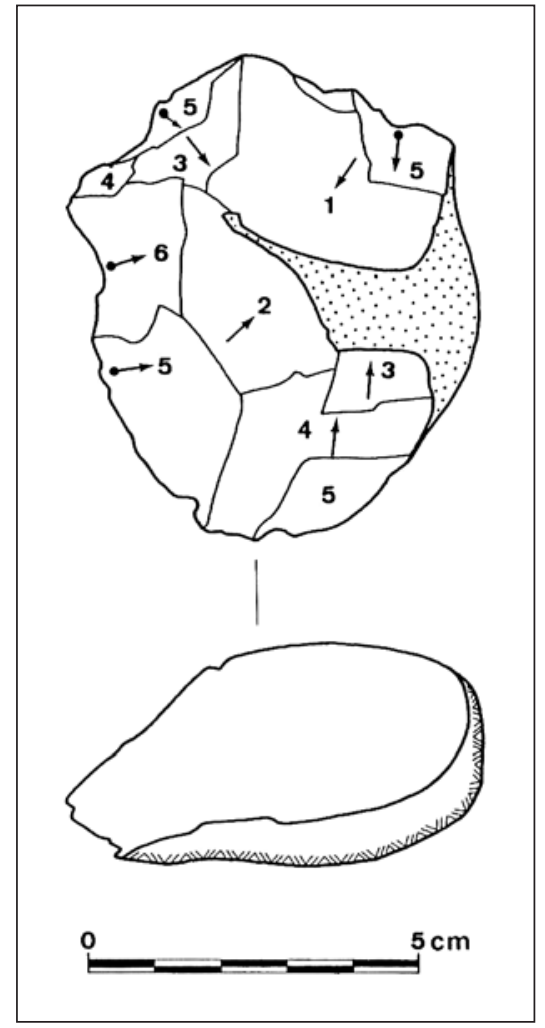

Fig. 6. Desenho diacrítico de um núcleo do grupo III sobre calhau rolado.

Fig. 6. Diacritical sketch of a core from the group III on a quartzite pebble.

dos casos revelando-se mesmo esgotada, o que deixa entrever a sua importância no contexto das estratégias de debitagem que caracterizam a indústria lítica da jazida de Castelo Velho 2.

O outro grupo de núcleos com alguma expressão quantitativa no âmbito desta indústria, o grupo V, reúne um conjunto de 8 peças, 7 das quais sobre calhau rolado. Mas se algumas delas evidenciam um grau de exploração incipiente que permite mesmo sugerir a sua aproximação a outros grupos de núcleos caracterizados por estratégias de exploração menos estruturadas, outras revelam-se intensamente exploradas. Nesta última situação as peças envolvidas apresentam em geral uma acentuada extensão periférica do talhe bifacial e alternante que as caracteriza, constituindo assim claras formas de transição para o grupo VII (Fig. 8), mesmo se nenhum dos núcleos inventariados foi na prática a ele associado.

Resulta assim clara a partição dos núcleos estudados na jazida do Castelo Velho 2 por duas cadeias operatórias de debitagem centrípeta, separadas entre si pela exploração unifacial e bifacial dos seus produtos finais e respectivas pré-formas, corresponden-

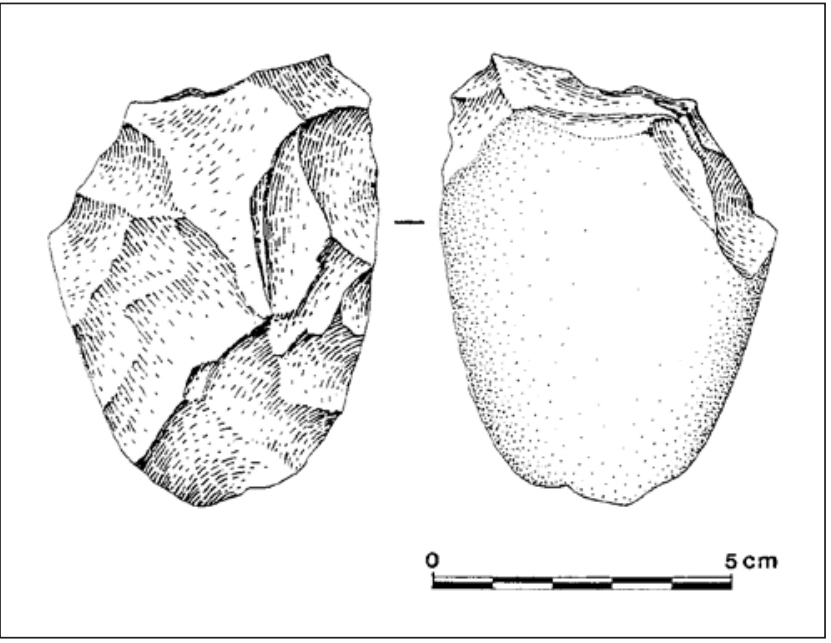

Fig. 7. Núcleo do grupo III desenvolvido sobre um núcleo do subgrupo Vic.

Fig. 7. Core from the group III developed from an old core of the subgroup Vic.

do sempre a segunda opção a um desenvolvimento alternante do talhe das suas duas faces. Mesmo quando as pré-formas configuram formalmente, no início da sua exploração, estratégias de debitagem associáveis a outras categorias classificativas de núcleos.

Esta realidade não esgota, porém, a totalidade dos núcleos representados nesta indústria lítica. No entanto, para além de alguns, poucos, núcleos associados a estratégias de exploração relativamente incipientes, as nove peças integradas no grupo IV, embora constituam uma forma expedita e oportunista de debitagem, conduzindo a intensificação da sua exploração ao aparecimento de formas poliédricas, não correspondem aparentemente, no contexto desta jazida, a uma cadeia de debitagem autónoma. Da observação de algumas das suas peças com uma exploração menos intensiva, resulta claro que se enveredou pelo desenvolvimento desta estratégia de debitagem como forma de readequar ou mesmo reaproveitar núcleos fracturados ou esgotados, frequentemente associados, na sua origem, a outros grupos de núcleos integrados nas duas cadeias operatórias principais já identificadas.

Os utensílios estão representados na indústria lítica recolhida na jazida de Castelo Velho 2 por um conjunto de 19 peças, que constituem $6,6 \%$ da totalidade dos materiais estudados.

Dezassete dessas peças correspondem a utensílios sobre lasca, quase todas de quartzito e evidenciando arestas de talhe vivas. Apenas se assinalou a presença de um utensílio definido sobre uma lasca de quartzo e de um outro, sobre uma lasca de quartzito, com as arestas de talhe relativamente embotadas. 


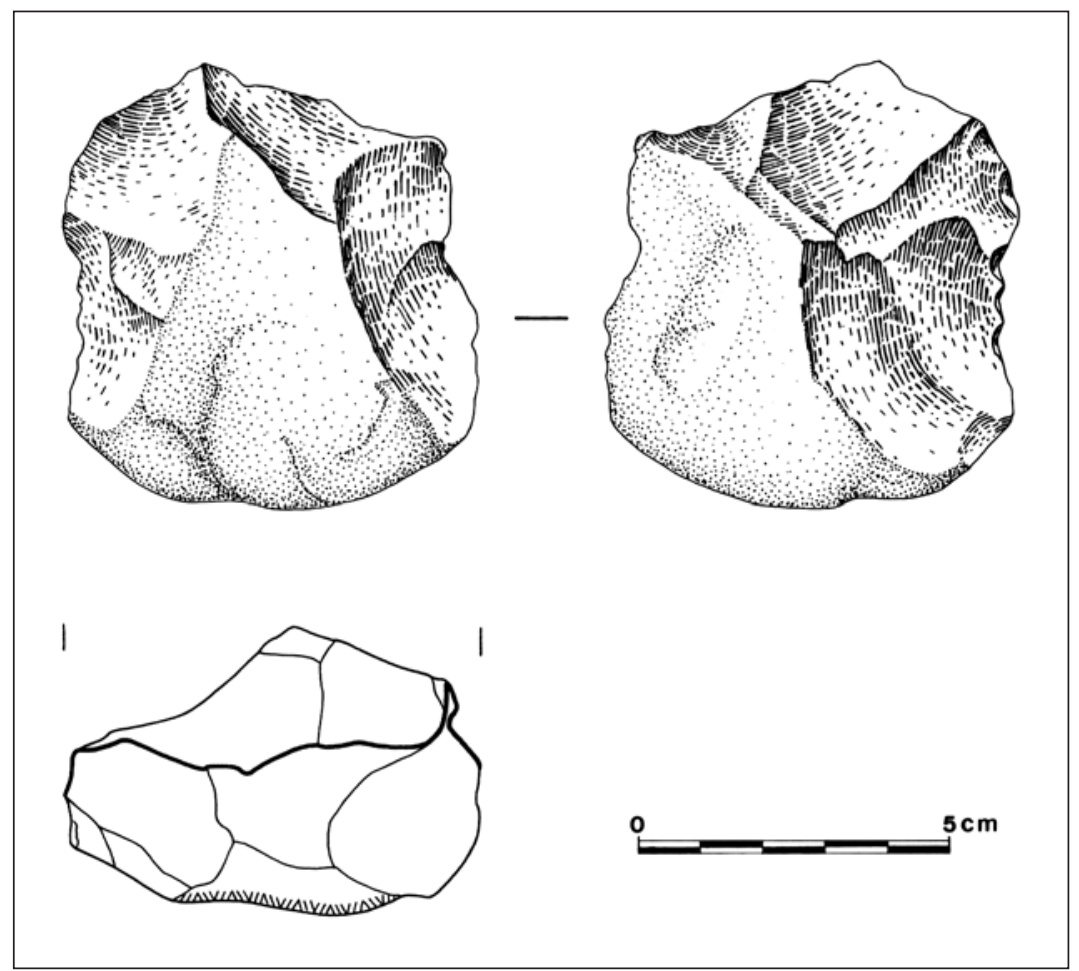

Fig. 8. Núcleo bifacial do grupo V sobre calhau rolado.

Fig. 8. Bifacial core from the group $\mathrm{V}$ on a quartzite pebble.

Entre os suportes utilizados predominavam as lascas de primeira geração e com talão cortical.

Os utensílios sobre lasca correspondem a peças cuja elaboração assentou na transformação por retoque de determinadas lascas, o que resultou na definição de uma área activa com características e dimensões variáveis em função do tipo de utensílio criado. À parte dois utensílios sobre lasca relativamente atípicos, os restantes 15 repartem-se equitativamente, em termos tipológicos, entre os raspadores, os denticulados e os entalhes.

Um dos utensílios sobre lasca considerado relativamente atípico apresentava como atributo morfológico identificativo a presença de um pequeno espigão na intersecção do bordo direito com o bordo distal da lasca suporte, espigão esse destacado por dois levantamentos adjacentes e posteriormente retocado, sugerindo-se a sua classificação como furador atípico. A segunda peça, por seu turno, foi classificada como raspadeira inversa, sendo definida por uma frente activa destacada no bordo esquerdo de uma lasca de descorticagem por dois levantamentos inversos, frente essa em seguida grosseiramente retocada.

Os raspadores, num total de cinco peças, correspondem maioritariamente a artefactos com um gume convexo. Os três raspadores laterais contabilizados - um dos quais sobre face plana - foram definidos a partir de lascas de segunda geração, enquanto os dois raspadores transversais, incluindo também um sobre face plana (Fig. 9, 1), têm como suporte lascas de primeira geração. Por seu turno, os denticulados foram maioritariamente elaborados a partir de lascas de primeira geração, na sua totalidade com talão cortical, incidindo tal transformação em três das peças inventariadas na respectiva face plana (Fig. 9, 3). Quanto aos entalhes, independentemente da sua diversificada posição nas lascas suporte, é de salientar a circunstância de a maioria destes utensílios terem sido também elaborados a partir de lascas de primeira geração, apresentando-se todos eles retocados. A única excepção reporta-se a um entalhe de incidência inversa e não retocado, definido por um único e reentrante levantamento em posição distal numa lasca de descorticagem cuja face de lascamento se apresenta adelgaçada por diversas extracções, o que permite classificá-lo como clactonense (Fig. 9, 2).

Note-se que este conjunto de utensílios sobre lasca era ainda complementado por um grupo de 18 lascas, duas das quais em sílex, com retoques expressivamente desenvolvidos ao longo dos seus bordos, muito embora a transformação induzida por tal operação não permitisse a sua associação a qualquer dos grupos tipológicos tradicionalmente identificados no estudo destas indústrias, tendo sido apenas classificadas como lascas retocadas. 


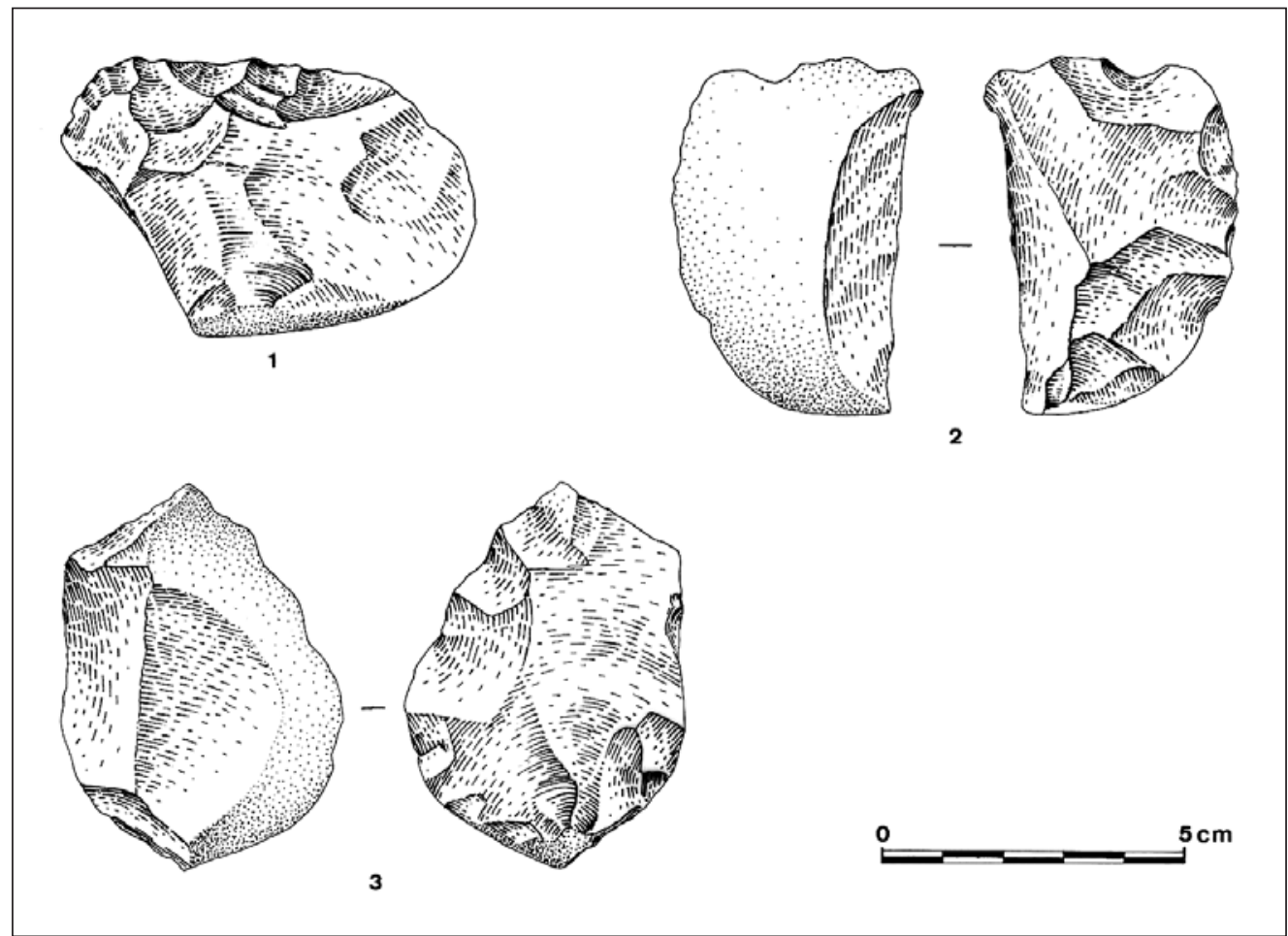

Fig. 9. Utensílios sobre lasca. 1 - raspador transversal; 2 - entalhe clatonense; 3 - denticulado. Fig. 9. Flake tools. 1 - transversal scraper; 2 - single notch; 3 - denticulate.

Por último, incluíram-se ainda no grupo dos utensílios duas peças resultantes da parcial reconfiguração por talhe ou retoque de suportes nucleares, designadas por esta mesma razão e para as individualizar dos utensílios sobre lasca como utensílios nucleiformes. No primeiro caso estudado tratava-se de um seixo talhado bifacial (chopping-tool), resultante da transformação da extremidade de um calhau rolado de quartzito de médias dimensões por talhe bifacial, tendo a incidência sequencial da extracção dos levantamentos em cada uma das faces permitido definir claramente um operacional gume rectilíneo. A segunda peça resultou da reutilização de um núcleo centrípeto intensamente explorado e sem preparação do respectivo plano de percussão (subgrupo VIc), através da criação num dos seus bordos de um gume denticulado, definido por três levantamentos entalhantes e adjacentes com aparentes vestígios de utilização.

\section{EPÍLOGo}

A identificação da jazida paleolítica do Castelo Velho 2 permitiu reunir um conjunto significativo de peças líticas talhadas em posição manifestamente secundária, muito embora a concentração de materiais reunidos no interior da coluvião e a proporção entre lascas e núcleos aí observada permita admitir que os vestígios arqueológicos exumados não terão sido muito deslocados da posição em que originalmente foram abandonados, conferindo ao conjunto em apreço uma relativa homogeneidade.

Da análise do espólio recolhido resulta claro, por seu turno, a sua associação a uma indústria lítica baseada na exploração dos recursos locais de matéria-prima, disponíveis sobre a forma de calhaus rolados de quartzito de média dimensão, revelando o sistema de produção de materiais líticos subjacente a presença exclusiva de cadeias operatórias de debitagem, não Levallois, onde as estratégias de exploração centrípetas dos núcleos assumem uma posição predominante. Estas características, juntamente com a inventariação de um pequeno conjunto de utensílios, quase exclusivamente constituídos por utensílios sobre lasca, sugerem a sua integração nas indústrias mustierenses do Paleolítico Médio, cuja presença na região do Médio Tejo se encontra há muito documentada em diferentes contextos geológicos e geográficos (CARDOSO 2006).

Não se dispondo de momento de qualquer dado cronométrico que permita estabelecer, mesmo que por aproximação, a antiguidade do depósito coluvionar e dos vestígios arqueológicos nele integrados, há que tentar balizar a sua datação com base nos dados actualmente disponíveis. 
Em termos estratigráficos, da análise do corte que secciona os vários depósitos existentes na área do Castelo Velho (Fig. 3), resulta claro que a coluvião se desenvolveu sobre as duas formações fluviais do rio Tejo aí representadas (Ft4 e Ft5), qualquer uma delas, associada na região, à presença de indústrias líticas acheulenses do Paleolítico Inferior (CUnHA Ribeiro et al. 1995). Mas se pela sua posição estratigráfica é evidente que a génese da coluvião ocorreu num momento posterior ao dos dois terraços do Tejo, o solo vermelho bem desenvolvido que lhe está associado pouco se diferencia dos solos que afectam qualquer uma das formações fluviais atrás referidas, distinguindo-se em contraponto da formação fluvial mais recente do rio Tejo - Ft6 - que suporta um solo bastante menos expressivo, o que constitui um indício significativo da relativa antiguidade da coluvião.

Pode-se assim considerar que a coluvião se terá desenvolvido após a deposição da formação fluvial Ft5 e antes do início da deposição da formação fluvial Ft6. Ora, admitindo a hipótese de se correlacionar as formações fluviais identificadas na margem direita do rio Tejo na região de Torres Novas, entre a ribeira da Ponte da Pedra e a foz do rio Alviela, com as formações similares estudadas no sector do Tejo imediatamente a montante, entre Vila Nova da Barquinha e Santa Cita, em Tomar (MARTINS et al. 2010b), as datações actualmente disponíveis para estas últimas (MARTINs et al. 2010a) permitiriam balizar o desenvolvimento da coluvião entre a deposição de Ft5 (equivalente ao T5, datado de 136-75 ka, MIS 5) e a deposição Ft6 (equivalente ao T6, datado de 62-30 ka, MIS3), o que se afigura totalmente compatível com a associação da indústria nele exumada a uma fase antiga do Paleolítico Médio, muito embora só o futuro desenvolvimento de um projecto de datação das formações quaternárias da região de Torres Novas permita validar ou não tais ilações.

A possibilidade de uma datação mais antiga para a indústria estudada, admitindo-se a sua remobilização a partir do parcial desmantelamento do terraço mais antigo (Ft4), não sendo descartável, obrigaria a repensar o significado da presença de materiais acheulenses em associação com a formação fluvial mais recente (Ft5). Tão pouco seria uma situação muito compatível com o estado físico bem preservado da maioria das peças estudadas e a sua apreciável concentração.

Em todo caso, independentemente do momento em que terá ocorrido a fixação, ainda que temporária, do homem do Paleolítico Médio na área do Castelo Velho, esta não pode ser dissociada da topografia de que o local já então disporia, da sua proximidade em relação a alguns corredores estratégicos de passagem na região e da diversidade de recursos disponíveis localmente e na área envolvente.

No momento em que o homem do Paleolítico Médio aí terá chegado, a plataforma aplanada que a preservação da formação fluvial $\mathrm{Ft} 4$ ainda hoje define a SSW da povoação de Riachos encontrava-se já delimitada pelo progressivo encaixe da rede de drenagem local, provavelmente até com um maior destaque do que nos dias de hoje, em virtude de um entalhe mais profundo que o actual do rio Almonda. A partir daí seria já então possível controlar uma vasta área envolvente, na transição da vasta planície aluvial adjacente do rio Tejo para as colinas miocénicas que se espraiam até à base do Maciço Central Estremenho, onde a presença do homem do Paleolítico Médio se encontra bem documentada em contextos arqueológicos cavernícolas, testemunhando uma ocupação prolongada no tempo, ainda que algo intermitente (ZILHÃo 2006). A posição estratégica do local era ainda reforçada pela sua proximidade do vale do rio Almonda que, juntamente com os vales de alguns dos seus afluentes, constituíam corredores naturais de comunicação e acesso entre o Maciço Central e a planície do rio Tejo. A todas estas vantagens da plataforma do Castelo Velho acrescia ainda a diversidade de recursos de que o homem do Paleolítico Médio aí dispunha, tanto pela abundância no local da matéria-prima indispensável para a manufactura dos seus artefactos, como também pela caça e pelos alimentos de origem vegetal que a proximidade do rio Almonda e do rio Tejo proporcionariam, ainda que as propriedades azóicas das formações quaternárias da região não tenham permitido deles conservar quaisquer testemunhos.

\section{BIBLIOGRAFIA}

Cardoso, J.L. 2006. The Mousterian Complex in Portugal. Zephyrus 59: 21-50.

CUnHA-RiBeiro, J.P. 1996-1997. Os machados de mão no Paleolítico Inferior português. Portugalia 17-18. Nova Série: 23-50.

Cunha-Ribeiro, J.P.; Maurício, J. \& Souto, P. 1995. O Paleolítico Inferior na região de Torres Novas. Novos elementos para o seu estudo, Nova Augusta 9: 45-71.

CUNHA-RiBeIRo, J.P. 1992-1993. Contribuição para o estudo do Paleolítico do vale do rio Lis no seu contexto crono-estratigráfico. Portugalia 13-14. Nova Série: 7-137.

Cunha-Ribeiro, J.P. 1999. O Acheulense no Centro de Portugal: o Vale do Lis. Contribuição para uma abordagem tecno-tipológica das suas indústrias líticas e problemática do seu contexto cronoestratigráfico. 3 Vols. Lisboa: Fac. de Letras da Universidade de Lisboa (Tese de Doutoramento).

CUNHA-RiBeiro, J.P. 2011. O Paleolítico Inferior da região de Torres Novas revisitado. Arkeos 28 (no prelo). 
Martins, A.A.; Cunha, P.P.; Buylaert, J.-P.; Huot, S.; MurRAY, A.S.; DinIS, P. \& STOKES, M. 2010a. K-feldspar IRSL dating of a Pleistocene river terrace staircase sequence of the Lower Tejo River (Portugal, western Iberia), Quaternary Geochronology 5: 176-180.

Martins, A.A.; Cunha, P.P.; Rosina, P.; Oosterbeek, L.; Cura, S.; Grimaldi, S.; Gomes, J.; Buylaert, J.-P., MurRAY, A.-S. \& MATOS, J. 2010b. Geoarchaeology of Pleistocene open-air sites in the Vila Nova da Barquinha - Santa Cita area (Lower Tejo River basin, central Portugal). Proceedings of the Geologists' Association 121: 128-140.

SANTONJA, M. 1984-1985. Los núcleos de lascas en las industrias paleoliticas de la meseta española. Zephyrus 37-38: 17-33.
TAvoso, A. 1978. Le Paléolithique inférieur et moyen du Haut-Languedoc. Gisements des terrasses alluviales du Tarn, du Dadou, de l'Agout, du Sor et du Fresquel. Etudes Quaternaires 5. Paris: Éditions du Laboratoire de Paléontologie Humaine et de Préhistoire, 404 pp.

Zbyszewski, G.; Manuppella, G. \& Veiga Ferreira, O. 1971. Carta Geológica de Portugal na escala de 1/50 000. Notícia explicativa da folha 27-C, Torres Novas. Lisboa: Serviços Geológicos de Portugal, 46 pp.

Zbyszewski, G.; Veiga Ferreira, O.; Leitão, M. \& North, C.T. 1974. A estação paleolítica do Castelo Velho (Riachos, Torres Novas). Arqueologia e História 5. 9. ${ }^{a}$ Série: 55-68.

ZILHÃO, J. 2006. Chronostratigraphy of the Middle-to-Upper Paleolithic transition in the Iberian Peninsula. Pyrenae 37: 7-84. 